\title{
PENINGKATAN MANAJEMEN USAHA BERBASIS CREATIVE PACKAGING PADA UMKM "BAKPIA IVAN" DI DESA JANTEN, YOGYAKARTA
}

\author{
Rosalia Prismarini Nurdiarti*1, Astri Wulandari' ${ }^{2}$, Mutaqin Akbar ${ }^{3}$ \\ ${ }^{12}$ Fakultas Ilmu Komunikasi \& Multimedia, Universitas Mercu Buana Yogyakarta \\ ${ }^{3}$ Fakultas Teknologi Informasi, Universitas Mercu Buana Yogyakarta \\ email: rosa@mercubuana-yogya.ac.id
}

\begin{abstract}
"Bakpia Ivan" Small and Medium Business Unit is managed by family and hereditary manner, so that several times there are employee turnover and sometimes causes the production process to be slightly inhibited. Another thing that is a problem is the lack of awareness of the product packaging process that is able to attract consumer interest and from the side of packaging security. This problem is linear unoptimal brand awareness and brand patent rights, so that when the product arrives at the reseller, the packaging is often replaced with other brands even though the contents are Bakpia Ivan. The purpose of this public service activity, first is to increase awareness of product packaging, positioning. Secondly, providing socialization and training about creative packaging, starting from the most basic capabilities. The method used in this activity is socialization and training. First, socializing and demonstrating how to begin packaging. Secondly, renew the logo design. Third, conduct social experiments related to logo renewal. The result of this activity is the acceptance of product packaging updates by the market so it can be expand sales and market segmentation. Second, the renewal of the logo / packaging design will be increasingly recognized and realized loyal consumers.
\end{abstract}

Keywords: creative packaging, bakpia ivan, segmentation, positioning

\section{Abstrak}

Unit Usaha Kecil dan Menengah "Bakpia Ivan” dikelola secara kekeluargaan dan turun temurun, sehingga beberapa kali terdapat pergantian karyawan dan kadang menyebabkan proses produksi sedikit terhambat. Hal lain yang menjadi permasalahan adalah minimnya kesadaran akan proses pengemasan produk yang mampu menarik minat konsumen dan melihat dari sisi keamanan kemasan. Problem ini linier dengan belum optimalnya kesadaran akan merk dan hak paten akan merk, sehingga ketika produk sampai pada reseller, kemasan sering diganti dengan merk lain meski isinya adalah Bakpia Ivan. Tujuan kegiatan pengabdian kepada masyarakat ini pertama adalah untuk meningkatkan kesadaran akan pengemasan produk dan positioning. Kedua, memberikan sosialisasi dan pelatihan tentang creative packaging mulai dari kemampuan yang paling dasar. Metode yang digunakan dalam kegiatan ini adalah sosialisasi dan pelatihan. Pertama, mensosialisasikan dan mendemonstrasikan bagaimana awal pembuatan kemasan. Kedua, memperbaharui design logo. Ketiga, melakukan eksperimen sosial terkait dengan pembaharuan logo. Hasil dari kegiatan ini adalah diterimanya pembaharuan kemasan produk oleh pasar sehingga mampu memperluas penjualan serta segmentasi pasar. Kedua, pembaharuan logo / design kemasan akan semakin dikenal dan terwujud konsumen yang loyal.

Keywords: creative packaging, bakpia ivan, segmentasi, positioning

\section{PENDAHULUAN}

Bakpia merupakan salah satu kuliner yang ikonik di Yogyakarta. Maka tak heran jika industri kuliner ini berkembang pesat seiring dengan permintaan konsumen. Dalam sejarahnya, bakpia diidentikkan dengan 
bisnis keluarga, oleh karenanya merk dagang dari setiap bakpia berbeda-beda disesuaikan dengan nomor rumah pembuatnya. Pada awalnya merk dagang bakpia hanyalah Bakpia Pathok yang disesuaikan dengan daerah pembuatnya. Lalu seiring dengan bertambahnya produsen bakpia, maka ditambahkan nomor rumah pembuatnya seperti bakpia pathok 25, bakpia pathok 75, bakpia pathok 65 dan lainnya (Karnadi, 2009 : 42).

Pada perkembangan selanjutnya, Pathok tidak lagi menjadi daerah khusus produksi Bakpia. Sehingga merk dagang bakpiapun berkembang tidak hanya terbatas nomor dan daerah, tetapi kebanyakan didasarkan pada nama pemilik atau inovasi produk yang dilakukan oleh produsen Bakpia tersebut, Beberapa merk bakpia seperti Kurnia Sari diproduksi di Glagahsari, Bakpia Ayu di Jalan Magelang, Bakpiapia Djogja di Jalan Wates atau Bakpia Kukus yang merupakan salah satu dari diversifikasi produk bakpia.

Tak terkecuali mitra pengabdian di sini, Bakpia Ivan yang juga merupakan bisnis keluarga. Nama tersebut diambil dari anak pemilik bakpia tersebut. Bakpia Ivan merintis usaha sekitar 14 tahun dengan Bapak Rikwanto dan Ibu Dwi Suprapti sebagai pemilik. Posisi produk dari mitra adalah segmentasi kelas menengah ke bawah dengan bahan baku kacang hijau asli (bukan kacang hijau kupas /premium). Bakpia Ivan memiliki sekitar delapan pekerja dan berproduksi setiap hari. Per hari mereka dapat memproduksi sekitar 3000 butir bakpia. Tetapi hal ini juga tergantung dengan jumlah SDM yang kadang berganti - berganti, sehingga menjadi salah satu kendala ketika proses produksi berlangsung.

Berkembangnya industri kuliner bakpia dan permintaan konsumen yang meningkat sekaligus kompetisi yang ketat, menjadikan UMKM seperti
Bakpia Ivan perlu untuk menjaga eksistensi yang telah belasan tahun dirintis. Apalagi kemunculan para pesaing baru dengan segala inovasi bakpianya, seperti bakpia kukus, bakpiapia kering dengan bentuk mirip kue nastar dan lainnya. Mereka tidak hanya berkreasi dari segi rasa dan bentuk bakpia tetapi juga dari aspek kemasan produk.

Distribusi yang masih terbatas dan bertahan pada segmentasi kelas menengah ke bawah, membuat daya jangkau konsumen juga terbatas. Jika diperhatikan lebih jauh, permasalahan secara khusus pada aspek kemasan produk, masih dalam bentuk plastik biasa dan belum mencantumkan masa kadaluwarsa. Hal lain, belum menonjolkan sisi keunggulan produk yakni enak, murah dan tanpa bahan pengawet. Selain itu produk belum terdaftar di BPOM dan belum memiliki hak paten merk. Permasalahan secara umum berkaitan dengan kesadaran akan merk dan positioning produk serta biaya produksi untuk kemasan yang terbatas.

Permasalahan serupa terkait dengan kemasan dan jaminan kemanan produk juga diulas dalam pengabdian di Kelompok Usaha Bersama (KUBE) Flower Cretive dan AlifDifa di Pekanbaru, dengan produk khas Melayu seperti bolu kemojo dan bolu ubi pelangi (Zen, dkk, 2018 : 106). Sejalan dengan hal tersebut, problem terkait branding produk, pembuatan logo dan merk dagang, dikaji dengan mengangkat masalah hasil olahan berbahan dasar terong di Kampung Liman Benawi yang mayoritas masyarakatnya adalah petani terong (Rumangkit, 2018 : 63).

Dari permasalahan tersebut, pengabdian ini bertujuan untuk pertama, meningkatkan kesadaran akan keamanan kemasan dan positioning. Kedua, memberikan sosialisasi dan pelatihan dasar creative packaging. Fungsi packaging bukan hanya sekedar untuk 
membungkus produk, tetapi juga memiliki kekuatan menjual (Sutiono, 2009 : 183). Desain kemasan dibuat berdasarkan pemahaman yang mendalam mengenai pasar dan konsumen, mempertimbangkan kebutuhan dan keinginan konsumen. Studi budaya dari aspek komunikasi membantu perancang dalam membuat kemasan yang cocok untuk suatu pasar. Oleh karena itu, kegiatan ini akan memberikan pemahaman yang berhubungan dengan creative packaging yang mampu memberikan identitas dan menjadi penciri dan pembeda sebuah produk.

\section{METODE PELAKSANAAN}

Pelaksanaan pengadian ini menggunakan beberapa metode untuk mendukung realisasi program PKM. Pertama, mengidentifikasi permasalahan terkait dengan keamanan kemasan produk dan hal lain yang berkaitan dengan packaging. Lalu dilanjutkan dengan kontrak awal untuk membangun kesepahaman mengenai tujuan dan pelaksanaan PKM antara tim dan mitra. Kedua, dengan transfer pengetahuan dan sosialisasi yang terkait dengan kesadaran akan merk dan positioning produk dalam menganalisis segmentasi pasar. Dilanjutkan diskusi mengenai logo yang sudah ada sebelumnya, bagaimana awal pembuatan dan latar belakang dipilih logo tersebut.

Ketiga, pelatihan, demonstrasi dan pendampingan untuk memperbaharui design kemasan. Pelatihan ini sekaligus untuk mengenalkan tahapan pembuatan design kemasan dari yang paling dasar. Dalam melakukan pendampingan juga akan berfokus pada partisipasi mitra dan juga pilihan segmentasi pasar yang sudah dipilih selama belasan tahun. Ketiga, melakukan eksperimen sosial dengan cara mensosialisasikan dan mendistribusikan kemasan baru pada konsumen serta melihat kesan, reaksi dan tanggapan mereka terhadap kemasan baru.

Pelaksanaan kegiatan ini dilaksanakan di rumah produksi bakpia ivan, dengan melibatkan pemilik bakpia ivan juga reseller yang menjual langsung pada konsumen di terminal dan tempat wisata. Kedua di Pasar Janten tempat produk didistribusikan. Program ini difasilitasi oleh narasumber yang memiliki keahlian dalam memberikan materi pelatihan di bidang design kemasan. Narasumber yang lain memberikan sosialisasi dan pendampingan dalam hal kesadaran merk, pemasaran dan positioning produk.

\section{HASIL DAN PEMBAHASAN}

Pada bulan Maret sampai April tim melakukan observasi dan penjajagan kembali ke UMKM Bakpia Ivan. Setelah melakukan koordinasi dengan salah satu owner Bakpia Ivan, kami menentukan beberapa hal yang menjadi acuan program. Pertama, label atau merk Ivan sudah belasan tahun dipakai sehingga kami tidak melakukan perubahan pada merk tersebut. Penyesuaian dilakukan pada cara pegemasan agar memenuhi standar keamanan. Kedua, kami mempelajari secara umum bagaimana proses produksi pembuatan bakpia ivan yang bisa dijamin tanpa bahan pengawet karena produk hanya bertahan maksimal lima hari dalam kondisi suhu ruangan.

Proses produksi meliputi : (1). Menjemur kacang hijau untuk menghilangkan kutu. (2) mencuci bersih kacang hijau. (3). Proses pengukusan kacang hijau. (4). Menggiling kacang hijau hingga lembut, lalu dimasak dengan mixer atau alat penggiling sambal dicampur gula pasir secukupnya (5). Pembuatan kulit atau bahan yang digunakan yaitu tepung terigu, gula pasir, air dan minya goreng, diaduk 
dalam mixer hingga kalis. (6) Proses pemanggangan atau dioven. (7). Proses pendinginan Bakpia. (8). Pengemasan.

Ada beberapa varian bakpia yang diproduksi yaitu bakpia basah denga nisi kacang hijau, bakpia coklat (bakpia kering isi gula jawa), bakpia potong keju dan bakpia goreng. Beberapa varian rasa tidak setiap hari diproduksi karena prosesnnya yang memakan waktu dan SDM yang terbatas, sehingga hanya diproduksi ketika ada permintaan. Omset harian yang diperoleh mitra berkisar dua juta hingga dua juta lima ratus ribu rupiah. Penjualan per pack (10 butir) adalah tiga ribu lima ratus rupiah. Jika permintaan sedang tinggi sementara SDM tidak mencukupi, mereka hanya memprioritaskan beberapa permintaan saja.

Dari sisi harga, produk bakpia ini memang menyasar pada segmentasi kelas menengah ke bawah dengan sistem penjualan langsung ke konsumen atau para pedagang makanan. Sedangkan untuk packaging produk dengan kemasan kota atau dus hanya diperuntukkan bagi konsumen yang memesan dengan jumlah tertentu dan biasanya diperuntukkan sebagai oleh oleh. Berikut gambar packaging bakpia ivan :

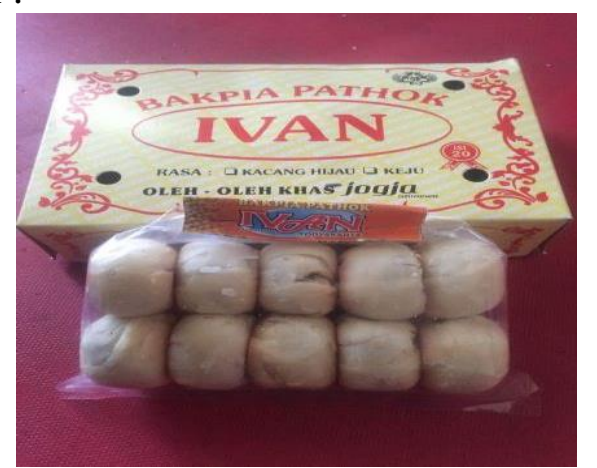

Gambar 1. Kemasan Plastik dan Kardus Pada kemasan platik hanya disteples dan diberi kertas label yang dicetak lembaran lalu kertas tersebut dipotong - potong secara manual. Kemasan kardus, secara umum mirip seperti background design pada bakpia pada umumnya dengan merk angka.
Mitra mengaku tidak mempunyai keberaian untuk menjual produk mereka dengan kemasan kotak di pasar, karena produk mereka menjadi kurang laku sebab harga menjadi relatif lebih mahal. Oleh karenanya hingga saat ini, mitra masih memilih kemasan plastik sebagai cara menginvasi pasar dan mempertahankan eksistensi poduk mereka. Pada produk yang memiliki fungsi untuk memenuhi kebutuhan sehari-hari, kecenderungan strategi desain adalah kesesuaian terhadap karakteristik konsumen. Sehingga seringkali membutuhkan kompromi terhadap pertimbangan penetapan harga dan feature produk (Masri, 2010 : 39).

Varian rasa bakpia ivan ini juga dikemas dengan cara yang sama. Menurut penuturan pemilik, pernah mereka menggunakan alat press plastik (hand sealer), tapi ternyata menurut mereka proses itu memakan waktu sehingga tidak bisa dilakukan secara efisien, sehingga mereka kembali ke cara yang lama, yaitu dengan steples. Varian produk / rasa bisa dilihat pada gambar berikut :

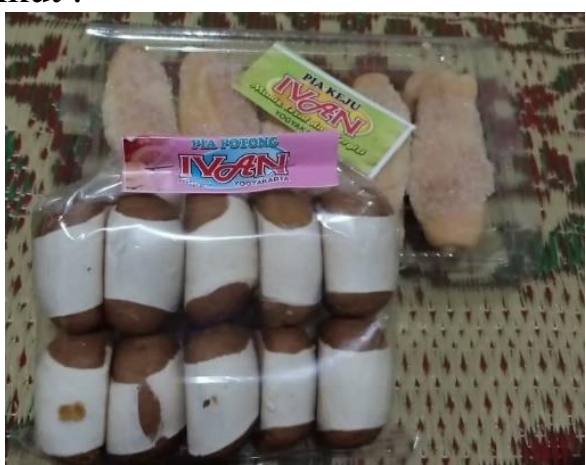

Gambar 2. Bakpia rasa keju dan coklat (gula jawa)

Kedua varian ini tergolong dalam bakpia kering. Pada produk rasa keju (label hijau) dikemas dengan plastik mika karena potongannya yang relatif panjang (berisi 10 butir). Sedangkan pada bakpia rasa coklat (gula jawa) dibungkus dengan kemasan plastik seperti bakpia rasa original (berisi 10 butir). 
Dengan melihat proses produksi sampai penjualan pada UMKM Bakpia Ivan, ada beberapa pendekatan yang dilakukan. Pertama berdasarkan metode yang sudah dipilih, yaitu sosialisasi dengan membangun kesadaran bahwa brand atau merk akan berkaitan dengan positioning produk di mata konsumen. Bagaimana mereka bisa dikenal, diidentifikasi melalui warna, bentuk, material atau gaya tipografi. Desain kemasan adalah bagian dari merk yang merepresentasikan produk. Peran desain kemasan akan efektif untuk menentukan target pangsa pasar yang jelas. Termasuk di dalamnya nilai, selera, gaya hidup dan kebiasaan konsumen (Klimchuk \& Krasovec, $2011:$ 35-37).

Dari hasil sosialisasi dan pemahaman akan kesadaran merk. Mitra dapat memahami bahwa suatu produk perlu memiliki identitas yang membedakan dari yang lain. Oleh karena itu, nama Ivan sebagai merek tidak mengalami perubahan dan secara tipografi huruf juga tidak mengalami perubahan. Ini sejalan dengan prinsip dasar desain yang meliputi elemen seperti garis, bentuk, warna dan tekstur. Pemahaman tata letak akan menentukan tujuan komunikasi visual. Selain ini aspek kontras yang berkaitan dengan skala, nilai yang diciptakan gelap terangnya warna dan intensitas akan menstimulasi ketertarikan visual konsumen (Setiawati, dkk, 2019 : 129130). Mitra memahami bahwa melalui logo, UMKM bisa membentuk komunikasi melalui tanda yang mudah dimengerti dan diingat oleh setiap orang. Mitra juga bisa mengidentifikasi bahwa pilihan target market pada kelas menengah ke bawah juga harus membentuk image dalam logo yang sudah dibuat.

Hasil berikutnya adalah mendemonstrasikan pembaharuan logo atau desain kemasan dalam beberapa bentuk atau varian kemasan. Pada tahap ini, mitra perlu pendampingan yang intensif, mengingat bahwa mereka sudah nyaman dengan pola pengemasan yang lama dan juga pertimbangan terbesar ada pada biaya produksi kemasan yang akan mengubah harga jual. Kemasan berupa plastik dapat dilihat pada gamar berikut :

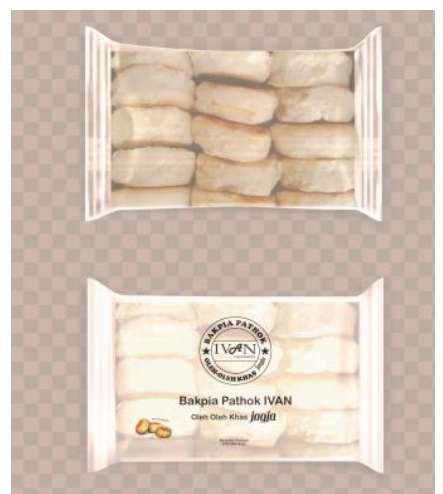

A

Gambar 3. Bakpia Kemasan Plastik

Pada kemasan plastik yang pertama dibuat trasnparan dengan ukuran panjang $15 \mathrm{~cm}$ dan lebar $10 \mathrm{~cm}$, yang masing - masing pacs berisi 10 butir bakpia. Estimasi harga kemasan plastik dua ratus lima puluh rupiah. Dalam model kemasan ini, logo disablon di atas plastik, dilengkapi dengan tanggal kadaluwarsa, varian rasa, dan desain dibuat sederhana, mengingat segmentasi pasar dan biaya produksi.

Demonstrasi pembaharuan logo dan juga kemasan lain yang ditawarkan masih dalam bentuk plastik, hanya dengan ketebalan yang berbeda dan masih bisa direkatkan lagi ketika sudah dibuka (ziplock / zipper pouch). Desain ini dibuat dengan mempertimbangkan keamanan dan kepraktisan produk ketika dibawa dan masih aman disimpan ketika produk tidak langsung habis dikonsumsi. Berikut gambar kemasan plastik versi kedua : 


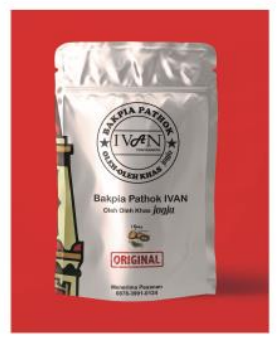

Gambar 4. Kemasan plastik B

Ukuran dari kemasan dengan panjang $15 \mathrm{~cm}$, lebar $10 \mathrm{~cm}$, berisi 15 butir bakpia dalam satu kemasan. Harga kemasan dengan model seperti ini tujuh ratus lima puluh rupiah per plastik.

Selain konsep kemasan plastik, kemasan kardus juga menjadi pilihan ketika ada pesanan dari luar kota. Jenis kemasan ini dipilih agar lebih ramah lingkungan. Gambar kemasan kardus, didesain sebagai berikut :

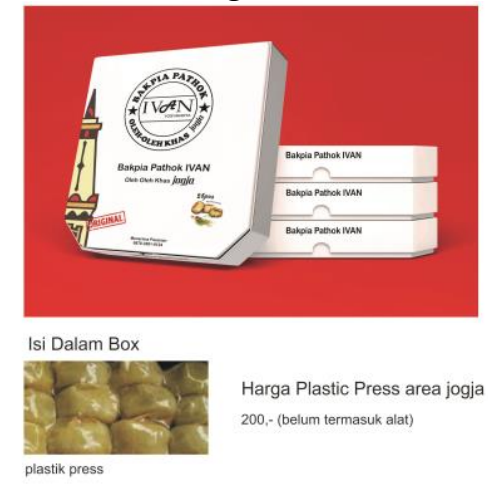

Gambar 5. Kemasan Kardus dan plastik press

Pada kemasan kardus agak sedikit berbeda, karena produk dilapisi dengan plastik yang dipress supaya kedap udara dan tahan lama ketika akan dibawa ke luar kota. Lalu dimasukkan ke dalam kardus, dengan ukuran panjang $20 \mathrm{~cm}$, lebar $20 \mathrm{~cm}$ dan tinggi $8 \mathrm{~cm}$. Isi bakpia 25 butir. Harga per box tiga ribu lima ratus rupiah. Sementara plastik press dua ratus rupiah (belum termasuk alat).

Tiga model pembaharuan kemasan dan logo ini melalui beberapa tahap, yaitu pengenalan dan koordinasi dengan mitra. Lalu selanjutnya digunakan terlebih dahulu kemasan plastik A karena pertimbangan biaya produksi dan harga jual. Identitas huruf / tipografi tetap seperti awal agar karakteristiknya mudah dikenali oleh konsumen. Gambar logo tugu Yogya sebagai pendukung ikon kota dan sejalan dengan bakpia sebagai kuliner khas. Dengan begitu tujuan utama promosi penjualan tercapai melalui komunikasi merk yang cepat dan jelas (jaminan merk) dan jenis produk (atribut produk).

Proses selanjutnya adalah dengan melakukan eksperimen sosial, berkaitan dengan kesan dan tanggapan konsumen tentang kemasan dan pembaharuan logo. Pada awalnya mitra ragu untuk merealisasikan mengingat akan mengubah harga untuk menutup biaya pengemasan produk. Lalu produk dengan kemasan plastik A, diuji coba terlebih dahulu untuk melihat bagaimana reaksi pasar apakah masih mengenali produk bakpia ivan. Pada bulan pertama, masih belum ada feedback yang berarti karena seolah memperkenalkan "produk baru", padahal merk tersebut sudah dikenal oleh kalangan menengah ke bawah. Pada bulan ketiga baru terlihat reaksi dari komentar positif dan pembelian masih lancar serta terjangkau ketika harga sedikit naik.

\section{SIMPULAN}

Dari hasil pembahasan dan ulasan di atas, ada beberapa kesimpulan yang bisa diambil, yaitu :

1. Produk UMKM Bakpia Ivan mampu menjaga eksistensinya di tengah persaingan ketat dan hadirnya kompetitor dengan berbagai varian baru dari bakpia. Mitra konsisten dengan segmentasi pasar di kelas menengah ke bawah, salah satunya untuk menjaga stabilitas harga produk.

2. Pengenalan pembaharuan logo dan kemasan memerlukan proses 
dan waktu berbulan- bulan supaya konsumen bisa mengidentifikasi kembali dan menerima produk. Bentuk huruf / tipografi yang masih sama, bukan merupakan jaminan akan mudah dikenal ketika kemasan secara material berubah.

3. Program yang berkaitan dengan pelatihan dasar- dasar desain kemasan, kesadaran akan merk dan positioning serta pendampingan perlu dilakukan pada UMKM serupa mengingat massifnya perkembangan kuliner bakpia di Yogyakarta dengan segala inovasinya.

\section{UCAPAN TERIMAKASIH}

Terimakasih kepada Kementrian Riset, Teknologi, dan Pendidikan Tinggi Republik Indonesia melalui Direktur Penelitian dan Pengabdian kepada Masyarakat atas dukungan pendanaan tahun 2019. Terimakasih atas dukungan Lembaga Penelitian dan Pengabdian Masyarakat Universitas Mercu Buana Yogyakarta, tim reviewer internal dan kolega di Fakultas Ilmu Komunikasi dan Multimedia, serta Fakultas Teknologi Informasi. Terimakasih untuk kerjasama rumah produksi Bakpia Ivan, serta partisipasi para mahasiswa tim produksi Laboratorium Ilmu Komunikasi.

\section{DAFTAR PUSTAKA}

[1]. Karnadi, H, 2009 dalam Koskow \& Sutrisno, 2009. Irama Visual dari Toekang Reklame Sampai Komunikator Visual. Yogyakarta. Jalasutra

[2]. Klimchuk, Rosner \& Krasovec, Sandra, 2011. Desain Kemasan (terj.). Jakarta. Erlangga

[3]. Masri, A, 2010. Strategi Visual. Yogyakarta. Jalasutra

[4]. Rumangkit, S, 2018. Peningkatan ekonomi Masyarakat Melalui
Olahan Kreatif dan Branding, Pekanbaru. Jurnal Pengabdian Untuk Mu NegeRI, 2 (1) : 62-65. URL

http://ejurnal.umri.ac.id/index.php /PengabdianUMRI/article/view/68 4/368 diakses 29 Agustus 2019

[5]. Setiawati, SD, Renasari, M, Fitriawati, D, 2019. Strategi Membangun Branding Bagi Pelaku Usaha Mikro Kecil Menengah. Jurnal Abdimas BSI, 2 (1) : 125-136. URL : https://ejournal.bsi.ac.id/ejurnal/in dex.php/abdimas/article/view/486 4/2942 diakses 25 Juli 2019

[6]. Sutrisno, J, 2009. Visual Merchandising Attraction. Jakarta. Gramedia

[7]. Zen, ZH, Anggraini, DA dan Yohanes, 2018. PKM Kelompok Usaha Bersama (KUBE) Aneka Cemilan Khas Melayu di Kel. Tampan, Pekanbaru. Jurnal Pengabdian Untuk Mu NegeRI, 2 (2) : 104-109. URL : http://ejurnal.umri.ac.id/index.php /PengabdianUMRI/article/view/82 4/671 diakses 29 Agustius 2019 